
\title{
is Research Square \\ Ozone Pollutants and the Onset of COVID-19 Symptoms in Chiba Prefecture, Japan
}

\author{
Hang Viet Dao \\ Hanoi Medical University \\ Katrina Fanjul \\ Kokusai Iryo Fukushi Daigaku \\ Ngoan Tran LE ( $\sim$ letngoan@hmu.edu.vn ) \\ Hanoi Medical University https://orcid.org/0000-0001-7862-492X
}

\section{Research}

Keywords: Ozone-pollutant, coronavirus-COVID-19, susceptibility

Posted Date: July 6th, 2020

DOI: https://doi.org/10.21203/rs.3.rs-38594/v1

License: (c) (1) This work is licensed under a Creative Commons Attribution 4.0 International License. Read Full License 


\section{Abstract \\ Background}

We examined the association between ozone pollutants in the breathing air and the onset of symptoms of COVID-19 infection.

\section{Methods}

We accessed online data of positive COVID-19 cases published by the Chiba Prefectural Government, including their ID, residence, age, sex, the dates of onset of symptoms, and tested positive with COVID-19. The daily data ozone concentrations were derived from an online database of 20 weather stations in the prefecture. The data of daily onset of symptoms of 735 patients were linked with the daily data of ozone concentrations. We estimated the number of daily person-years by dividing the number of the population by 365 (days). The incidence rate ratio and $95 \%$ confidence interval (IRR, 95\% $\mathrm{Cl}$ ) were estimated by the levels of ozone concentrations.

\section{Results}

There was a significant positive association between the date of symptom onset and levels of ozone concentrations. Adjusted IRR, 95\% Cl, tertile_3 vs. tertile_1, was $1.69(1.26,2.26)$ for total participants, $p$ for trend $=0.000$. The positive association was observed in women but not in men, adjusted IRR, $95 \% \mathrm{Cl}$, tertile_3 vs. tertile_1: $3.18(1.94,5.22)$, and $1.07(0.73,1.57)$, respectively. The positive association was seen for the sub-groups of ages under 60 but not $60+$, adjusted IRR, $95 \% \mathrm{Cl}$, tertile_3 vs. tertile_1: 1.90 $(1.37,2.65)$ and $1.10(0.57,2.17)$, respectively.

\section{Conclusions}

Ozone pollutants affect susceptibility to COVID-19 in the onset of symptoms. The findings warrant further studies on the mechanism of how ozone pollutants affect susceptibility to COVID-19.

\section{Background}

WHO estimates air pollution causes nearly 7 million premature deaths annually worldwide. In the U.S., the estimated mortality risk per $10 \mu \mathrm{g} / \mathrm{m} 3$ increment of an air pollutant is significantly increased for all causes of death, and the sub-group causes of the cardiopulmonary, cardiovascular, cerebrovascular systems, cancers, and influenza/pneumonia [1]. Because air pollution increased a person's susceptibility to the 1918 Spanish Influenza, about 3,400-5,860 pandemic-related infant deaths could have been linked to air pollution in the U.S. in 1918 [2]. 
The first positive case of COVID-19 was reported on 30 January 2020 in Chiba Prefecture, Japan, a patient from Wuhan City, China. The number of positive patients was 779 (mild or moderate condition: 459 cases, $59 \%$ ), severe (12 cases, $2 \%$ ), death (34 cases, 4\%), discharge ( 274 cases, $35 \%$ ) by 8 May 2020 . Chiba had a population of 6,259,000 people in November 2019 and the population remained stable during the first quarter of 2020 when we conducted this study. Chiba is one of 47 prefectures in Japan and located in the Kanto region. Chiba is the sixth most populous prefecture and the capital being Chiba City. The prefecture shares borders with three other prefectures which are Ibaraki, Saitama, and Tokyo.

For air quality monitoring, the Chiba prefectures have 20 weather stations represented ecological regions and produce species of ozone (03), SO2, NO2, CO, PM10, and PM2.5 (fine particle matter with a diameter of $2.5 \mu \mathrm{m}$ or less). Ozone is generated from anthropogenic emissions of $\mathrm{NO}, \mathrm{NO} 2$, and $\mathrm{CO}$ in the presence of solar irradiation. Ozone in the stratosphere can move down to the troposphere, contributing to the "background" level of ground-level ozone. Ozone concentrations were high enough to exert acute effects such as eye and nasal irritation, respiratory disease emergencies, lung function impairment, and inflammation of the airways in the general population [3].

Specific features of the COVID-19 pandemic are person-to-person transmission by close physical contact with the positive patients during a timeline of his/her disease progressing[4,5]. However, only about $4 \%$ (328 cases) of 8,169 people having close physical contact with positive patients tested positive with COVID-19 [6]. There are unknown factors that affect susceptibility to COVID-19, which may include environmental factors, especially air pollution in general or individual specie of ozone.

\section{Objectives}

This work aims to examine the association between ozone pollutants in the breathing air and the onset of symptoms of COVID-19 infection.

\section{Methods}

\section{Study population and setting}

The method of population-based registration of incidence case series was applied and performed for the whole population of Chiba prefecture, Japan from January to May 2020. The first case with reported COVID-19 symptoms was reported in Chiba prefecture on 20 January and was later confirmed positive on 31 January 2020. Out of 735 cases for the final data analysis, there were 9 foreign patients including 4 from Wuhan city, China; 30 participants from other prefectures; 686 participants were residents of 38 cities/towns of Chiba prefecture, and 10 cases did not consent to publish their residential status. On 7 April, Chiba was one of six prefectures proclaimed to be in a state of emergency from 8 April. Data of the daily reported cases confirmed positive with COVID-19 and the daily exposure to species of air pollution, including ozone pollutants, were created and examined.

\section{Population exposure to ozone estimation}


The daily data of ozone pollutants were derived from an online database of 20 weather stations throughout Chiba prefecture [7]. All 20 weather stations located in Chiba prefecture, representing different ecological regions, had information available on the following species of ozone; SO2, NO2, CO, PM10, and PM2.5 from 31 December 2013 to 30 April 2020. We calculated the daily mean ozone concentrations including other species of air pollution from the 20 weather stations for the present study. The first positive patient had reported that the onset of symptoms was on 20 January 2020 . The daily estimated mean concentrations of ozone from 20 January 2020 to 30 April 2020 was used to merge with the daily incidence cases of COVID-19 in our study population. The estimated mean concentrations of ozone pollutants during the study time from 20 January 2020 to 30 April 2020 was $36.97\left(\mu \mathrm{g} / \mathrm{M}^{3}\right)$, ranging from $20.80\left(\mu \mathrm{g} / \mathrm{M}^{3}\right)$ to $62.80\left(\mu \mathrm{g} / \mathrm{M}^{3}\right)$.

\section{Covariate variables}

Covariate variables included age group, sex, relative humidity, ambient temperature, $\mathrm{SO} 2, \mathrm{NO} 2, \mathrm{CO}, \mathrm{PM} 2.5$, and time of every 7 days of the timeline (To minimize effects of the season changing from winter to spring and early summer) that were included in the analysis model in controlling for confounding factors. For PM2.5, the estimated mean concentrations were $37.14\left(\mu \mathrm{g} / \mathrm{M}^{3}\right)$, ranging from $24.60\left(\mu \mathrm{g} / \mathrm{M}^{3}\right)$ to 61.00 $\left(\mu \mathrm{g} / \mathrm{M}^{3}\right)$. The estimated means of $\mathrm{CO}$ and SO2 were less than $3.00\left(\mu \mathrm{g} / \mathrm{M}^{3}\right)$. For $\mathrm{CO}$, the estimated mean was $2.31\left(\mu \mathrm{g} / \mathrm{M}^{3}\right)$, ranging from $1.50\left(\mu \mathrm{g} / \mathrm{M}^{3}\right)$ to $5.00\left(\mu \mathrm{g} / \mathrm{M}^{3}\right)$. For SO2, the estimated mean was 1.78 $\left(\mu \mathrm{g} / \mathrm{M}^{3}\right)$, ranging from $1.00\left(\mu \mathrm{g} / \mathrm{M}^{3}\right)$ to $3.80\left(\mu \mathrm{g} / \mathrm{M}^{3}\right)$. For relative humidity and ambient temperature, we derived data from the Air Quality Historical Data Platform from January 2020 to date, on the COVID-19 data page [7]. This database was missing data on relative humidity and ambient temperature from 10 to 24 February 2020. For this particular period, we obtained data on relative humidity and ambient temperature from the Narita Airport weather database[8].

\section{COVID-19 outcomes in Chiba prefecture}

The first case with reported COVID-19 symptoms was reported in Chiba prefecture on 20 January 2020. The last patient, during this study time, had reported the onset of symptoms on 30 April 2020. By 3 May 2020, there were 866 positive patients reported in the Chiba prefecture. We excluded 131 participants because 99 asymptomatic patients until the date tested positive with COVID-19, 31 patients had not consented to public personal information, and one patient reported onset symptoms after the date tested positive with COVID-19. The remaining 735 participants were eligible for the final data analysis.

Patient information included ID, residence, age, sex, symptom onset date, and confirmation of testing positive with COVID-19. Data has been updated daily by the Chiba Prefecture Health and Welfare Department Disease Control Section regarding the information on ID, age, and sex, symptom onset and features, local and international travel, and social activities. For example, the first case report was published in a Press Release of "About outbreak of patients associated with new coronavirus (January $\left.31^{\text {st }}, 2019\right)$ " as follows "Patient aged 20s, female, the residence of Chiba; Symptoms and course: Cough and runny nose on 20 January 2020. On 29 January, she had visited a medical institution due to 
respiratory symptoms. On 30 January, a Public health center conducted a survey based on the recommendations of a contact survey from the Nara prefecture and collected samples for COVID-19 testing. On 16 January, she had traveled from Tokyo to Osaka by a plane. She participated in a tour for Chinese people as a bus guider from 17 to 22 January. On January 22, she moved from Osaka to Tokyo by bus. She had no overseas travel history within 2 weeks before the onset date (January 20) and wearied a mask from the end of the tour from 22 January 2020" [9].

The daily onset of symptoms data was linked with the daily ozone pollutant data. During the period from 20 January 2020 to 30 April 2020, there were 71 days where patients reported the onset of symptoms. The daily number of cases differed from one to another during these 71 days, Figure 1.

\section{Data handling and analysis}

We estimated the number of daily person-years by dividing the number of the population of $6,259,000$ by 365 (days). Exposure to ozone and other covariate variables was grouped into three levels. For tertile_1, tertile_2, and tertile_3, the estimated mean $\left(\mu \mathrm{g} / \mathrm{M}^{3}\right)$ of ozone concentrations was 29.2 (20.8-33.5), 36.7 (34.0-39.3), and 45.3 (39.4-62.8); the rounded number of person-years was $410,805,408,364$, and 393,981 ; the number of incidence cases positive with COVID-19 was 151, 212, and 371, respectively. The incidence rate ratio and $95 \%$ confidence interval (IRR, 95\% Cl) were estimated by the level of ozone concentrations using unconditional logistic regression analysis, adjusted for the age group (0-9, 10-19, 20-29, 30-39, 40-49, 50-59, 60-69. 7-79, and 80+), sex, relative humidity, ambient temperature, SO2, NO2, CO, PM2.5, and time of every 7 days of the timeline. All $p$-values were two-sided, and $p<5 \%$ (alpha value) was considered to indicate statistical significance.

\section{Ethical approval}

This study uses public data shared by Chiba prefecture, Japan from January to May 2020. This database does not contain any information used to identify patients including name, personal address, date of birth, etc. Patients are only referred to in numerical order, thus the consent of individuals is not required.

\section{Results}

For all 735 eligible study participants, there was a significant positive association between the date of symptom onset and levels of ozone pollutants in the breathing air. The estimated crude IRR, $95 \% \mathrm{Cl}$, tertile_3 vs. tertile_1, was $2.57(2.13,3.11), p$ for trend $=0.000$. The positive association remained after controlling for covariate variables. The adjusted IRR, $95 \% \mathrm{Cl}$, tertile_3 vs. tertile_1, was $1.69(1.26,2.26)$ for total participants, $p$ for trend=0.000, Table 1 .

For men, the estimated crude IRR, 95\% Cl, tertile_3 vs. tertile_1, was $2.12(1.67,2.69), p$ for trend $=0.000$. The positive association was not statistically significant after controlling for covariate variables. Adjusted IRR, 95\% Cl, tertile_3 vs. tertile_1, was $1.07(0.73,1.57)$, $p$ for trend=0.198. For women, the estimated crude IRR, $95 \%$ Cl, tertile_3 vs. tertile_1, was $3.28(2.39,4.49)$, $p$ for trend=0.000. Adjusted IRR, 95\% Cl, tertile_3 
vs. tertile_1, was $3.18(1.94,5.22)$, $p$ for trend=0.000. For the median level of ozone pollutants, when compared to the lowest level, the risk of symptom onset was significantly increased in women but not in men; The adjusted IRR, 95\% Cl, tertile_2 vs. tertile_1, was $2.48(1.61,3.81)$ and $0.61(0.45,0.83)$, respectively, Table 2 .

The significant positive association also remained for the sub-groups of ages under 60 but not for the aging patients with aged $60+$, the adjusted IRR, $95 \% \mathrm{Cl}$, tertile_3 vs. tertile_1, was $1.90(1.37,2.65)$, $p$ for trend $=0.000$ and $1.10(0.57,2.17), p$ for trend $=0.505$, respectively, Table 3.

The significant positive association also remained for the sub-groups of suspected time for 1-5 days and 6-26 days; the adjusted IRR, 95\% Cl, tertile_3 vs. tertile_1, was $1.50(1.00,2.26), p$ for trend $=0.033$ and 1.48 $(0.97,2.26), p$ for trend $=0.004$, respectively, Table 4 .

\section{Discussion}

The significant positive association between the level of ozone concentrations in the air and the onset of symptoms among incidence cases tested positive with COVID-19 suggests that ozone pollutants in particular and air pollution in general affect susceptibility to COVID-19, the pathogen of the current ongoing pandemic due to coronavirus.

The present findings are consistent with the previous studies on air pollution and viral infection due to influenza. In the U.S., long-term exposure to fine particulate matter air pollution (PM2.5) significantly increased mortality due to influenza/pneumonia by $47 \%$ [1]. About an estimated $3,400-5,860$ pandemicrelated infant deaths may have been linked to air pollution in the U.S. in 1918 [2]. Ozone pollutants were associated with an increased risk of pediatric influenza by $26 \%$ in Brisbane, Australia [10].

Inhaled ozone pollutants cause remarkably reversible acute lung function changes and inflammation. Investigators indicate the critical role of mediators including IL-1, IL-17, and IL-33 in driving ozone effects on airway inflammation [11]. Surface macrophages and epithelial cells are involved in the activation of epithelial NFkB and generation of pro-inflammatory mediators such as IL-6, IL-8, TNFa, IL-1b, ICAM-1, Eselectin, and PGE2 [12]. The macrophages have been shown to protect ozone-exposed mice from inflammation [13]. The role of macrophages with ozone exposure in the airway surface liquid is complex since they may be activated by ozone to secrete cytokines that communicate with epithelial cells but also protectively scavenge lipid ozonation products [12].

The symptom of patients infected with SARS-CoV-2 ranges from minimal symptoms to severe respiratory failure with multiple organ failure. By 9 May 2020, there were 779 positive patients reported in Chiba Prefecture, including 471 current infected cases (mild and moderate 459 patients, severe 12 patients); 274 cases had completed medical treatments and discharged from hospitals, and death cases were 34 . There were additional 100 cases tested positive with COVID-19 by this date as the group of asymptomatic patients [9]. In the severe patients confirmed positive with COVID-19, the pathology of COVID-19 is the production of inflammatory cytokines such as IL-1, IL-6, IL-8, and TNF-a, which attract 
alveolar macrophages, neutrophils (IL-8), and induce alveolar and interstitial inflammation [14]. Severe COVID-19 infection is characterized by a massive pro-inflammatory response or cytokine storm that results in acute respiratory distress syndrome and multi-organ dysfunction[14]. A combination of ozone exposure and positive infection with COVID-19 might greatly increase an acute respiratory distress syndrome and induced severe acute respiratory syndrome in developing severe bilateral pneumonia, multiple mottling, and ground-glass opacity, and pneumothorax [15].

From 8 December 2019, some cases of novel acute severe pneumonia of unknown underlying cause had been reported in Wuhan, Hubei province, China. In the initial stages of this serious respiratory disease, severe acute respiratory infection symptoms occurred, with some patients rapidly developing acute respiratory distress syndrome [15]. The first cluster included patients from the local Huanan seafood wholesale market, where live animals were also on sale. Thus, the ongoing coronavirus pandemic initially occurred from a polluted microenvironment of the live seafood wholesale market. However, as far as we know to date, there aren't any available published articles on the association between air pollution and COVID-19 occurrence.

COVID-19 is one of seven members of the family of coronaviruses that infect humans, in which three members are deadly pathogens named SARS-CoV (occurred during 2002-2003), MERS-CoV (occurred during 2012-2015), and COVID-19 (occurring from December 2019 to date). Coronaviruses are enveloped RNA viruses that cause respiratory, enteric, hepatic, and neurologic diseases in humans, birds, and other mammals [16]. The respiratory and digestive tracts are the two main systems initially affected by the lifethreatening viral pathogen with the presence of varied symptoms including fever, cough, shortness of breath, muscular aches, confusion, headaches, sore throat, rhinorrhea, chest pain, diarrhea, and nausea and vomiting [15]. People who are aging and/or have underlying health conditions are at a greater risk of fatal pneumonia due to COVID-19 than other people with a healthy history [17]. Regarding air pollution, ozone pollutants can irritate the lining of the nose, airway, and lungs and induce inflammation $[18,19]$. Ozone pollutants may increase the risk of respiratory tract infections and might affect susceptibility to COVID-19.

The mechanism of how ozone pollutants affect susceptibility to COVID-19 is unclear to date. Further investigations of the association between air pollution and susceptibility to COVID-19 are warranted. Ozone exposure significantly increases the adhesion of polymorphonuclear leukocytes to human respiratory tract epithelial cells [20]. Investigators have found that exposure to ozone pollutants disrupts the protease, anti-protease balance seen in the airway, contributing to an increased risk of viral infection [21]. In experimental animals, ozone exposure is collectively associated with greater overall inflammation and epithelial cell death [22]. The first and most likely possible explanation is that the patient acquired the infection and Ozone pollutants act as a co-factor induces both inflammations of the respiratory tract and enhances the viral agent in developing clinical courses. Because about $96 \%$ of people had close contact with COVID-19 positive patients but they were not infected [6]; therefore, ozone might enhance COVID-19 among patients acquired the infection-induced symptoms and developing clinical courses of the disease from the date of the onset of symptoms. About 11\% (99 of 866 cases) of patients acquired the infection 
was not presented clinical symptoms or asymptomatic in the present study population. This fact suggested that there are potential unknown environmental factors involved in developing severe COVID19 disease. The toxic chemical specie of ozone pollutants may be responsible for affecting COVID-19 susceptibility. Another possible explanation is that patients acquired the infection after developing respiratory tract inflammations due to ozone pollutant exposures. However, this possibility is less likely as people would have taken measures such as self-isolation, using a facial mask, or keeping social distance if they presented with any symptoms of upper respiratory infection, as a guideline by public health authorities.

In the present study, the sub-group of women and the group aged under 60-year-old at a higher risk of the onset of symptoms due to COVID-19 infection than the subgroups of men and aging people. Further investigations of the underlying causality of this association between an affect susceptibility to COVID19 in women and young ages are warranted.

The limitation of this study is the lack of direct measures of individuals exposed to ozone pollutants in breathing air. Within Chiba Prefecture, 20 weather stations are representing each ecological region, therefore, the present estimation of ozone exposures would be represented an exposure to the toxic chemical in breathing air. We used the date of symptom onset, wherein many patients; this might not reflect the date of exposure to COVID-19, because the estimated incubation time is 5.2 days [23]. Despite this limitation, the present findings add new evidence of the association between air pollution and the onset of COVID-19 symptoms. To reduce the burden of the ongoing pandemic, there should be more importance placed on air pollution control.

\section{References}

1. C.A. Pope, 3rd, J.S. Lefler, M. Ezzati, J.D. Higbee, J.D. Marshall, S.Y. Kim, M. Bechle, K.S. Gilliat, S.E. Vernon, A.L. Robinson, R.T. Burnett, Mortality Risk and Fine Particulate Air Pollution in a Large, Representative Cohort of U.S. Adults, Environ Health Perspect 127 (2019) 77007.

2. Karen Clay, Joshua Lewis, Edson R. Severnini, IZA DP No. 9399: Pollution, Infectious Disease, and Mortality: Evidence from the 1918 Spanish Influenza Pandemic, 2015.

3. J.J. Zhang, Y. Wei, Z. Fang, Ozone Pollution: A Major Health Hazard Worldwide, Front Immunol 10 (2019) 2518.

4. J.F. Chan, S. Yuan, K.H. Kok, K.K. To, H. Chu, J. Yang, F. Xing, J. Liu, C.C. Yip, R.W. Poon, H.W. Tsoi, S.K. Lo, K.H. Chan, V.K. Poon, W.M. Chan, J.D. Ip, J.P. Cai, V.C. Cheng, H. Chen, C.K. Hui, K.Y. Yuen, A familial cluster of pneumonia associated with the 2019 novel coronavirus indicating person-toperson transmission: a study of a family cluster, Lancet (2020).

5. L.T. Phan, T.V. Nguyen, Q.C. Luong, T.V. Nguyen, H.T. Nguyen, H.Q. Le, T.T. Nguyen, T.M. Cao, Q.D. Pham, Importation and Human-to-Human Transmission of a Novel Coronavirus in Vietnam, $\mathrm{N}$ Engl $\mathrm{J}$ Med (2020). 
6. Ministry of Health, Ministry of Health - Monitoring Pneumonia COVID-19, Viet Nam, Updated on 2020/06/03 11:00 AM, Ministry of Health, Viet Nam, Updated on 2020/06/03 11:00 AM, https://ncov.moh.gov.vn/, 2020.

7. AQICN.ORG, Air Quality Historical Data Platform - Institution \& University Registration, available at https://aqicn.org/data-platform/register/, 2020.

8. NOAA, NOAA's National Centers for Environmental Information Formerly the National Climatic Data Center (NCDC), available at https://www.ncdc.noaa.gov/data-access/quick-links, 2020.

9. Chiba Prefectural Government, About outbreak of patient, new coronavirus infectious disease, Chiba Prefectural Government, https://www.pref.chiba.lg.jp/shippei/press/2019/ncov-index.html, 2020.

10. Z. Xu, W. Hu, G. Williams, A.C. Clements, H. Kan, S. Tong, Air pollution, temperature and pediatric influenza in Brisbane, Australia, Environ Int 59 (2013) 384-388.

11. S. Mumby, K.F. Chung, I.M. Adcock, Transcriptional Effects of Ozone and Impact on Airway Inflammation, Front Immunol 10 (2019) 1610.

12. P.A. Bromberg, Mechanisms of the acute effects of inhaled ozone in humans, Biochim Biophys Acta 1860 (2016) 2771-2781.

13. M. Dahl, A.K. Bauer, M. Arredouani, R. Soininen, K. Tryggvason, S.R. Kleeberger, L. Kobzik, Protection against inhaled oxidants through scavenging of oxidized lipids by macrophage receptors MARCO and SR-Al/II, J Clin Invest 117 (2007) 757-764.

14. K. Yuki, M. Fujiogi, S. Koutsogiannaki, COVID-19 pathophysiology: A review, Clin Immunol 215 (2020) 108427.

15. N. Chen, M. Zhou, X. Dong, J. Qu, F. Gong, Y. Han, Y. Qiu, J. Wang, Y. Liu, Y. Wei, J. Xia, T. Yu, X. Zhang, L. Zhang, Epidemiological and clinical characteristics of 99 cases of 2019 novel coronavirus pneumonia in Wuhan, China: a descriptive study, Lancet (2020).

16. N. Zhu, D. Zhang, W. Wang, X. Li, B. Yang, J. Song, X. Zhao, B. Huang, W. Shi, R. Lu, P. Niu, F. Zhan, X. Ma, D. Wang, W. Xu, G. Wu, G.F. Gao, W. Tan, A Novel Coronavirus from Patients with Pneumonia in China, 2019, N Engl J Med (2020).

17. C. Huang, Y. Wang, X. Li, L. Ren, J. Zhao, Y. Hu, L. Zhang, G. Fan, J. Xu, X. Gu, Z. Cheng, T. Yu, J. Xia, Y. Wei, W. Wu, X. Xie, W. Yin, H. Li, M. Liu, Y. Xiao, H. Gao, L. Guo, J. Xie, G. Wang, R. Jiang, Z. Gao, Q. Jin, J. Wang, B. Cao, Clinical features of patients infected with 2019 novel coronavirus in Wuhan, China, Lancet (2020).

18. WHO, Air pollution, Health Topics, WHO, WHO Home, 2020.

19. CDC, Air quality Ozone and Your Health; Air Pollutants, CDC, CDC Home, 2020.

20. M.F. Tosi, A. Hamedani, J. Brosovich, S.E. Alpert, ICAM-1-independent, CD18-dependent adhesion between neutrophils and human airway epithelial cells exposed in vitro to ozone, J Immunol 152 (1994) 1935-1942.

21. M.J. Kesic, M. Meyer, R. Bauer, I. Jaspers, Exposure to ozone modulates human airway protease/antiprotease balance contributing to increased influenza A infection, PLoS One 7 (2012) 
e35108.

22. S.R. Murphy, K.L. Oslund, D.M. Hyde, L.A. Miller, L.S. Van Winkle, E.S. Schelegle, Ozone-induced airway epithelial cell death, the neurokinin-1 receptor pathway, and the postnatal developing lung, Am J Physiol Lung Cell Mol Physiol 307 (2014) L471-481.

23. Q. Li, X. Guan, P. Wu, X. Wang, L. Zhou, Y. Tong, R. Ren, K.S.M. Leung, E.H.Y. Lau, J.Y. Wong, X. Xing, N. Xiang, Y. Wu, C. Li, Q. Chen, D. Li, T. Liu, J. Zhao, M. Li, W. Tu, C. Chen, L. Jin, R. Yang, Q. Wang, S. Zhou, R. Wang, H. Liu, Y. Luo, Y. Liu, G. Shao, H. Li, Z. Tao, Y. Yang, Z. Deng, B. Liu, Z. Ma, Y. Zhang, G. Shi, T.T.Y. Lam, J.T.K. Wu, G.F. Gao, B.J. Cowling, B. Yang, G.M. Leung, Z. Feng, Early Transmission Dynamics in Wuhan, China, of Novel Coronavirus-Infected Pneumonia, N Engl J Med (2020).

\section{Tables}

Table 1: Incidence rate ratio by the level of Ozone concentration, all study participants

\begin{tabular}{|llllll|}
\hline $\begin{array}{l}\text { Ozone } \\
(\mathrm{O})\end{array}$ & $\begin{array}{l}\text { Mean } \\
(\mu \mathrm{g} / \mathrm{M} 3)\end{array}$ & $\begin{array}{l}\text { Person } \\
\text { year\# }\end{array}$ & $\begin{array}{l}\text { Case } \\
(\mathrm{n}=735)\end{array}$ & $\begin{array}{l}\text { Crude IRR } \\
(95 \% \mathrm{Cl})\end{array}$ & $\begin{array}{l}\text { Adjusted IRR* } \\
(95 \% \mathrm{Cl})\end{array}$ \\
\hline tertile_1 & 29.20 & 410,805 & 151 & 1.00 (reference) & 1.00 (reference) \\
\hline tertile_2 & 36.70 & 408,364 & 212 & $1.41(1.15,1.74)$ & $1.00(0.78,1.28)$ \\
\hline tertile_3 & 45.30 & 393,981 & $372 \$$ & $2.57(2.13,3.11)$ & $1.69(1.26,2.26)$ \\
\hline$p$ for trend & & & & 0.000 & 0.000 \\
\hline
\end{tabular}

IRR $(95 \% \mathrm{Cl})$ : Incidence rate ratio and 95\% confidence interval; \# Rounded number; \$ Excluded one case not consent information of sex; *Adjusted for the age group (0-9, 10-19, 20-29, 30-39, 40-49, 50-59, 60-69. $7-79$, and $80+$ ), sex, relative humidity, ambient temperature, SO2, NO2, CO, PM2.5, and time of every 7 days of the timeline. 
Table 2: Incidence rate ratio by the level of Ozone concentration and by sex

\begin{tabular}{|lllcc|}
\hline & Ozone $(03)$, Mean $(\mu \mathrm{g} / \mathrm{M} 3)$ & Case & Crude IRR $(95 \% \mathrm{Cl})$ & Adjusted IRR $(95 \% \mathrm{Cl})^{\star}$ \\
\hline Men & 29.20 & 99 & $1.00($ reference $)$ & 1.00 (reference) \\
\hline & 36.70 & 139 & $0.91(0.70,1.18)$ & $0.61(0.45,0.83)$ \\
\hline Total & 45.30 & 225 & $2.12(1.67,2.69)$ & $1.07(0.73,1.57)$ \\
\hline$p$ for trend & & 463 & & 0.198 \\
\hline Women & 29.20 & & 0.000 & $1.00($ reference $)$ \\
\hline & 36.70 & 52 & $1.00($ reference $)$ & $2.48(1.61,3.81)$ \\
\hline Total & 45.30 & 73 & $2.64(1.85,3.77)$ & $3.18(1.94,5.22)$ \\
\hline$p$ for trend & & 147 & $3.28(2.39,4.49)$ & 0.000 \\
\hline
\end{tabular}

IRR (95\% Cl): Incidence rate ratio and 95\% confidence interval; *Adjusted for the age group (0-9, 10-19, 20 29, 30-39, 40-49, 50-59, 60-69. 7-79, and 80+), sex, relative humidity, ambient temperature, SO2, NO2, CO, PM2.5, and time of every 7 days of the timeline.

Table 3: Incidence rate ratio by the level of Ozone concentration and by the sub-age-group

\begin{tabular}{|c|c|c|c|c|}
\hline & Ozone (03), Mean ( $\mu \mathrm{g} / \mathrm{M} 3)$ & Case & Crude IRR $(95 \% \mathrm{CI})$ & Adjusted IRR $(95 \% \mathrm{CI})^{\star}$ \\
\hline \multirow[t]{3}{*}{ Age $<60$} & 29.20 & 105 & 1.00 (reference) & 1.00 (reference) \\
\hline & 36.70 & 148 & $1.29(1.00,1.66)$ & $1.05(0.79,1.40)$ \\
\hline & 45.30 & 278 & $2.33(1.86,2.91)$ & $1.90(1.37,2.65)$ \\
\hline Total & & 531 & & \\
\hline$p$ for trend & & & 0.000 & 0.000 \\
\hline \multirow[t]{3}{*}{ Age 60+ } & 29.20 & 46 & 1.00 (reference) & 1.00 (reference) \\
\hline & 36.70 & 64 & $1.63(1.12,2.38)$ & $0.81(0.48,1.35)$ \\
\hline & 45.30 & 94 & $2.91(2.05,4.15)$ & $1.10(0.57,2.17)$ \\
\hline Total & & 204 & & \\
\hline$p$ for trend & & & 0.000 & 0.505 \\
\hline
\end{tabular}


IRR $(95 \% \mathrm{Cl})$ : Incidence rate ratio and $95 \%$ confidence interval

*Adjusted for the age group (0-9, 10-19, 20-29, 30-39, 40-49, 50-59, 60-69. 7-79, and 80+), sex, relative humidity, ambient temperature, SO2, NO2, CO, PM2.5, and time of every 7 days of the timeline.

Table 4: Incidence rate ratio by the level of Ozone concentration and by the sub-group of the suspected time

\begin{tabular}{|c|c|c|c|c|}
\hline & $\begin{array}{l}\text { Ozone }(03), \text { Mean } \\
(\mu \mathrm{g} / \mathrm{M} 3)\end{array}$ & Case & $\begin{array}{l}\text { Crude IRR } \\
(95 \% \mathrm{Cl})\end{array}$ & Adjusted IRR $(95 \% \mathrm{Cl})$ \\
\hline \multirow[t]{3}{*}{$\begin{array}{l}\text { Suspected time }<6 \\
\text { days }\end{array}$} & 29.20 & 64 & $\begin{array}{l}1.00 \\
\text { (reference) }\end{array}$ & 1.00 (reference) \\
\hline & 36.70 & 90 & $\begin{array}{l}\text { 1.17 }(0.85 \\
1.61)\end{array}$ & $1.11(0.77,1.61)$ \\
\hline & 45.30 & 161 & $\begin{array}{l}1.50(1.12, \\
2.00)\end{array}$ & $1.50(1.00,2.26)$ \\
\hline Total & & 315 & & \\
\hline$p$ for trend & & & 0.004 & 0.033 \\
\hline \multirow[t]{3}{*}{$\begin{array}{l}\text { Suspected time }>5 \\
\text { days }\end{array}$} & 29.20 & 87 & $\begin{array}{l}1.00 \\
\text { (reference) }\end{array}$ & 1.00 (reference) \\
\hline & 36.70 & 122 & $\begin{array}{l}1.44(1.03 \\
2.00)\end{array}$ & $0.81(0.57,1.15)$ \\
\hline & 45.30 & 211 & $\begin{array}{l}3.32(2.47, \\
4.47)\end{array}$ & $1.48(0.97,2.26)$ \\
\hline Total & & 420 & & \\
\hline$p$ for trend & & & 0.000 & 0.004 \\
\hline
\end{tabular}

IRR (95\% Cl): Incidence rate ratio and 95\% confidence interval

*Adjusted for the age group (0-9, 10-19, 20-29, 30-39, 40-49, 50-59, 60-69. 7-79, and 80+), sex, relative humidity, ambient temperature, $\mathrm{SO} 2, \mathrm{NO} 2, \mathrm{CO}, \mathrm{PM} 2.5$, and time of every 7 days of the timeline.

\section{Figures}



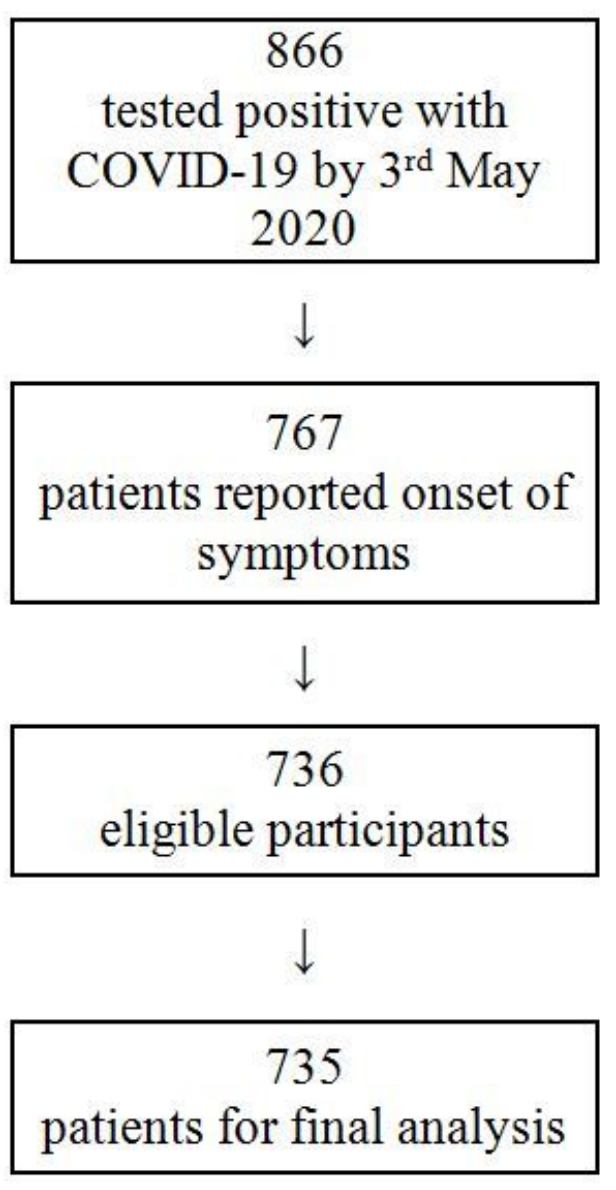

$\rightarrow \quad$ Excluded 99 asymptomatic patients until the date tested positive with COVID-19

Excluded 31 patients having not to consent to public personal information

$\rightarrow \quad$ Excluded one patient-reported onset symptoms after the date tested positive with COVID-19

Figure 1

Flow charge of selected study participants tested positive with COVID-19 by 3 May 2020 in Chiba Prefecture. 


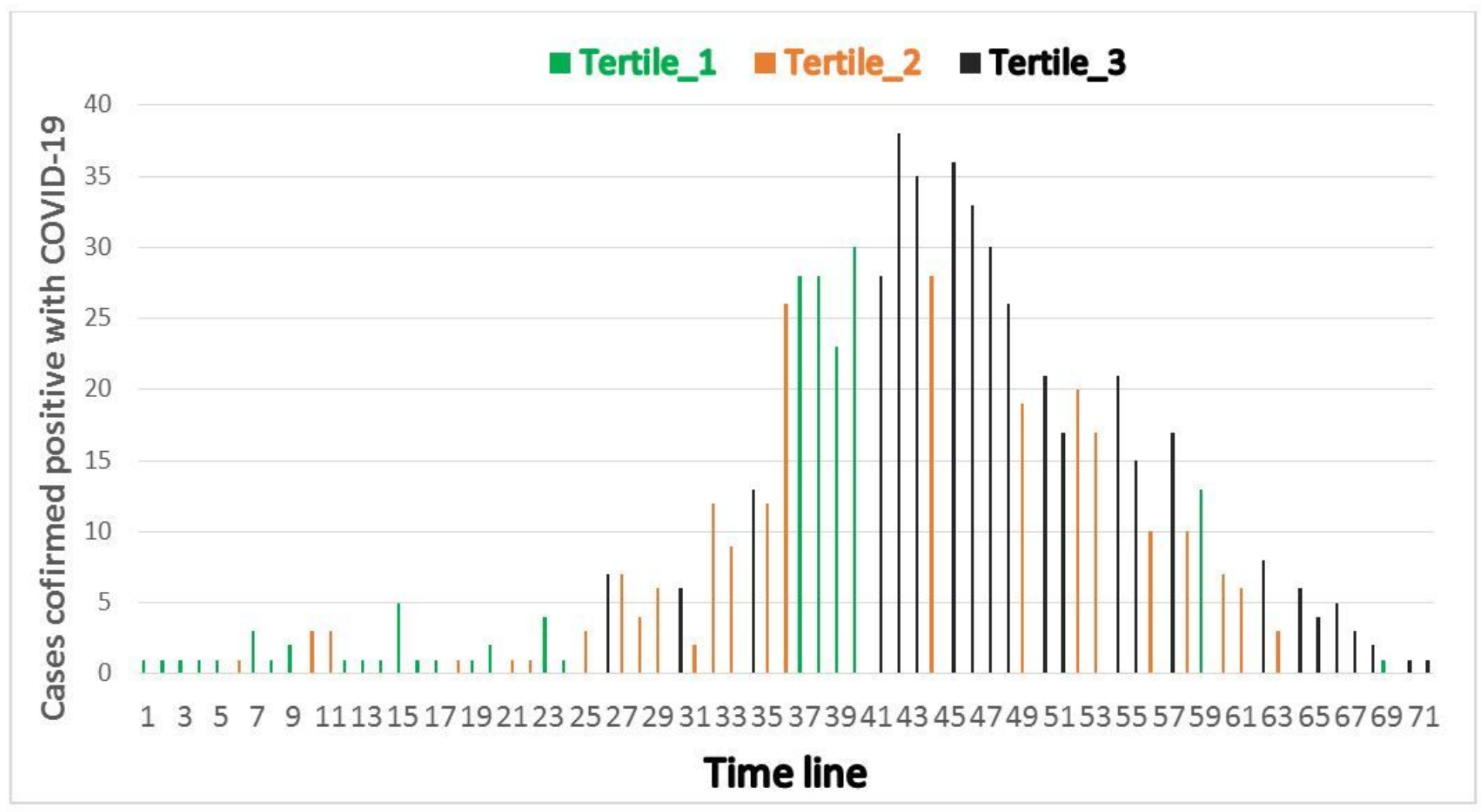

Tertile_1 (Green): Ozone ranking from 20.8-33.5 $\mu \mathrm{g} / \mathrm{M} 3$; Tertile_2 (Orange): 33.6-39.3 $\mu \mathrm{g} / \mathrm{M} 3$, Tertile_3 (Black): 39.4-62.4 $\mu \mathrm{g} / \mathrm{M} 3$. Count for days having at least one case presented onset of symptoms due to COVID-19 infection.

Figure 2

Timeline of cases confirmed positive with COVID-19 by levels of Ozone (03). 